\title{
ЛЕКСИКО-СЕМАНТИЧЕСКИЕ И ЛЕКСИКО-ТЕМАТИЧЕСКИЕ ОСОБЕННОСТИ РЕЧЕВОГО ПОРТРЕТА МУЖЧИНЫ-ПОЛИТИКА И ЖЕНЩИНЫ-ПОЛИТИКА
}

\section{LEXICO-SEMANTIC AND LEXICO-THEMATIC FEATURES OF THE SPEECH PORTRAIT OF A MAN-POLITICIAN AND WOMEN-POLITICIAN}

Du Shanshan

Summary: The image of politicians, constructed in the minds of the public by means of modern media, is incomplete without a speech portrait of a person as a significant element of his political representation. The speech portrait, in turn, is formed on the basis of lexical features, including the semantics and topics of texts addressed to the audience. In this article, the author analyzes the lexical-semantic and lexical-thematic features of the speech portrait of Western politicians, both men and women, in terms of their gender specificity. On the example of public speeches, addresses and debates, general and special features inherent in the semantics and themes of their speech are traced. In conclusion, the author makes an important conclusion about the degree of presence in public speech of «masculine» and "feminine» traits, their use depending on the ultimate goal and semantic content of the speech, the frequency of use and their ratio in male and female political communication, as well as on the main topic speeches of Western politicians.

Keywords: lexical-semantic features, lexical-thematic features, speech portrait, gender, woman-politician, man-politician, image, communicative personality image, political communication, masculine and feminine elements of speech.
$\mathrm{O}$ дним из важнейших направлений политической лингвистики на сегодняшний день выступает исследование вектора мышления политиков на основании особенностей их речевой коммуникации. Специфика семантики и тематики речи позволяет конструировать образ политического лидера в сознании граждан, составлять о нем представление, основываясь на коммуникативном имидже личности.

Формирование политического имиджа личности невозможно без внимания к ее речевым особенностям, создающим в сознании общественности представления о соотношении заявлений, сделанных в рамках речевой коммуникации, и их последующей практической реализации. В свою очередь, в зависимости от тех смыслов и тематики, которые составляют основу речевой коммуникации политика, с их реальных проявлений формируется уровень доверия общественности к по-
Ду Шаньшань

Аспирант, Санкт-Петербургский государственный университет

du.shanshan@bk.ru

Аннотация: Имидж политиков, конструируемый в сознании общественности посредством современных СМИ, неполноценен без речевого портрета личности как значимого элемента ее политической репрезентации. Речевой портрет, в свою очередь, формируется на основании лексических особенностей, В том числе - семантики и тематики текстов, обращенных к аудитории.

В настоящей статье автор анализирует лексико-семантические и лексико-тематические особенности речевого портрета западных политиков, как мужчин, так и женщин, в русле их гендерной специфики. На примере публичных выступлений, обращений и дебатов прослеживаются общие и особенные черты, свойственные семантике и тематике их речи.

В заключении автор делает важный вывод о степени наличия в публичной речи «маскулинных» и «фемининных» черт, их использования в зависимости от конечной цели и смысловой наполненности выступления, частоте употребления и их соотношении в мужской и женской политической коммуникации, а также об основной тематике выступлений западных политиков.

Ключевые слова: лексико-семантические особенности, лексико-тематические особенности, речевой портрет, гендер, женщина-политик, мужчина-политик, имидж, коммуникативный имидж личности, политическая коммуникация, маскулинные и фемининные элементы речи.

литическому лидеру. В этой связи следует согласиться с О.И. Гордеевой, что аудитория склонна воспринимать именно тот образ личности, который воспроизводится современными СМИ и генерируется самим субъектом $[2$, с. 170]. Речевая коммуникация при этом выполняет функцию трансляции наиболее значимых, ключевых посылов политика, формируя его имидж. Последний, в свою очередь, представляет собой обобщающее, концентрированное представление, транслируемое посредством СМИ аудитории [5, с. 66].

Семантические и тематические особенности текста различны с точки зрения гендерного аспекта его конструирования. Отличия между мужчинами и женщинами в сфере политики проявляются, в первую очередь, в особенностях их речи, без использования которой участие в политической жизни не представляется возможным. Семантика, т.е. смысловое наполнение речи, равно как 
и выбор темы коммуникации с аудиторией, имеет гендерную специфику. В комплексе они оказывают прямое влияние на коммуникативное поведение политического лидера как знаковую часть его профессиональной деятельности, что, в свою очередь, представляет собой одно из приоритетных направлений исследований в современной лингвистике. С точки зрения И.А. Стернина, коммуникативное поведение представляет собой систему норм и традиций общения народа, социальной, возрастной, профессиональной и иных групп [7, с. 3]. В этой связи выстраивание контакта коммуникатора с аудиторией в сфере политики представляет собой особенно актуальную область исследования в силу того, что политическая коммуникация сочетает в себе все необходимые компоненты норм и традиций общения: она социально заряжена, обращена к гражданам определенных возрастных и профессиональных категорий, выстраивается сообразно конкретным принципам, основываясь на конечной цели политического воздействия на аудиторию.

Специфику семантических и тематических особенностей лексики политиков целесообразно изучать на конкретных примерах. Однако, следует отметить наличие двух основных гендерных особенностей, присущих политическим выступлениям, а именно:

1. Политический имидж личности предъявляет требования к использованию в речи элементов, присущих как мужской, так и женской коммуникации. Это определяется стремлением политика оказать на публику воздействие необходимой глубины и направленности. В свою очередь, резкая смена стиля речевой коммуникации (переход от использования «фемининных» конструктов к «маскулинным», и наоборот) способствует реализации гендерного подхода к формированию речевого портрета политика;

2. Использование обращений к аудитории по гендерному принципу (так, призыв может быть осуществлен как к женской, так и к мужской части публики, с соответствующим использованием необходимых языковых средств). В этой связи в речи коммуникатора прослеживается использование с определенной периодичностью разного рода метафор, гендерных стереотипов, характерных стратегий общения и проч. Анализ особенностей лексико-семантического и лексико-тематического речевого портрета женщин-политиков и мужчинполитиков в рамках настоящей статьи будет производиться на примере западных политических лидеров. При этом в основу исследования будет положения система лингвистических средств, часто реализуемая конкретной языковой личностью.

Среди женщин-политиков одной из наиболее ярких фигур, на примере которой можно проследить характерные лингвистические особенности политической коммуникации, является Хилари Клинтон - значимая фигура американской политической арены, член Демократической партии, кандидат в президенты Соединенных Штатов на выборах 2016 г.

Строгость внешнего образа, и шире - имиджа Хилари Клинтон подчеркивается тональностью ее высказываний, их смысловой наполненностью, стремлением, присутствующим в используемых ею речевых конструкциях, поддерживать образ статусной и влиятельной женщины-политика.

Речевые элементы текстов Х. Клинтов, обращенных к аудитории, напрямую зависят от семантики и тематики ее выступлений. В частности, по поводу возможности получения Ираном доступа к ядерному вооружению, X. Клинтон позиционировала себя как жесткий и непримиримый политик, готовый идти до конца в случае нарушения соглашений с иранской стороны. Во время своего выступления в Брукингском исследовательском институте в г. Вашингтон Х. Клинтон заявила, что «... следует ожидать, что Иран попытается проверить на прочность будущего президента. Они захотят проверить, насколько далеко они могут зайти, нарушая правила» [4]. В свою очередь, на встрече с главой МИД России С. Лавровым X. Клинтон отмечала, что «Иран имеет право на развитие мирной ядерной энергетики, но не имеет права на обладание ядерным оружием» [3]. Употребление нескольких модальных глаголов политиком в рамках одного высказывания придает речи Х. Клинтон убедительный, повелительный характер. Кроме, того предложения с синтаксической структурой, используемые Х. Клинтон, являются легкими для восприятия аудиторией.

В речи политика сплетаются лингвистические особенности женской и мужской коммуникации, позволяющие ей оказывать необходимое влияние на публику, расставлять смысловые акценты. В ряде случаев тональность текстов, основной тематикой которых являются политические и экономические вопросы, намеренно усиливается за счет использования «мужских» агрессивных метафор. Характерным примером тому могут служить дебаты бывшего президента Соединенных Штатов - Б. Обамы с Х. Клинтон в Южной Каролине, в рамках которых последняя использовала преднамеренно агрессивную лексику. В частности, по сообщениям «The Wall Street Journal», Б. Обама в рамках дебатов начал такую словесную перепалку с Х. Клинтон, предъявив ей обвинение в том, что она изначально не включила малооплачиваемых и безработных рабочих в свое предложение по стимулированию американской экономики, что их дальнейший диалог перешел на крик: «Hard feelings between the two boiled over at the podium after weeks of campaign sniping between the camps over mostly trivial matters. Mr. Obama, a U.S. senator from Illinois, started the fusillade by accusing Mrs. Clinton, a New York senator, 
of initially failing to include low-wage and unemployed workers in her economic stimulus proposal. As tempers between the two candidates rose and they began shouting over each other, moderator Wolf Blitzer of debate sponsor CNN pleaded for calm» [13]. Эти дебаты вошли в историю как самые жестокие президентские дебаты сезона.

Высказывания Х. Клинтон в рамках дебатов в дальнейшем развивались в интервью, в частности, в том, которое она дала журналу «Atlantic» в августе 2014 г. Политик, подчеркнув, что ее критика в адрес Б. Обамы не имеет какого-либо личного подтекста, резко осудила его внешнеполитический курс, в особенности - расплывчатость и простоту его формулировок. По словам политика, «... Великим державам нужны организующие принципы, а не «не делай глупостей» [9]. По словам X. Клинтон, принцип, обозначенный Б. Обамой не способен был сплотить граждан и привести страну к лучшему будущему.

Главной семантической особенностью речи Х. Клинтон, в данном случае, являлось представление политических действий Б. Обамы в невыгодном свете. Выступление Х. Клинтон было построено на противопоставлении: возвеличивании собственной политической линии, и, одновременно, принижении внешнеполитического курса Б. Обамы. В этой связи, как дебаты с Б. Обамой, так и интервью Х. Клинтон наглядно демонстрируют, что далеко не всегда речевой портрет женщины-политика характеризует уступчивость, а мужчины-политика - агрессивные метафоры.

Также следует отметить, что по данным некоторых исследователей мужчины-политики не склонны дослушивать высказывания политических оппонентов-женщин до конца, вне зависимости от их тематики и смысловой нагрузки [12, с. 40]. Дебаты Б. Обамы с Х. Клинтон подтверждают обратное: агрессивная, уничижительная лексика женщины-политика, обвинения в адрес своего оппонента, отнюдь не вызвали желания у Б. Обамы перебить речь Х. Клинтон.

Наряду с «маскулинными» чертами, присутствующими в лексике Х. Клинтон, ее речи свойственны также «фемининные» черты. В частности, в языке женщины-политика достаточно часто встречаются лексико-грамматические эвфемизмы - особые речевые конструкции, призванные смягчить высказывание. Для речи Х. Клинтон характерно использование таких речевых элементов, как well (что ж), I mean (хочу сказать) и I think (думаю) и проч.

Несмотря на то, что понятие политического эвфемизма не является устойчивым, в лингвистике оно применяется достаточно широко. Существующие в науке дефиниции политического эвфемизма позволяют отличать его от эвфемизмов других видов. Их суть сводится к тому, что политический эвфемизм представляет собой смягчение или искажение неприятных аудитории фактов в тексте [8, с. 36-37].

В более узком смысле политические эвфемизмы следует понимать как конструкции, используемые в речи политиков для замены табуированных слов и выражений, в рамках конкретного этапа исторического развития общества, во избежание неприятных последствий в результате оскорбления чувств объекта коммуникации, либо воздействия на мнение общественности. В этой связи, политические эвфемизмы являются характерной лексико-семантической особенностью речи как женщин, так и мужчин-политиков.

Речевому портрету Х. Клинтон также свойственно использование политических эвфемизмов. Так, в своем выступлении на митинге в 2013 г. в Нью-Йорке она заявила: «And you know - In all of the states, you voted because you wanted a leader who will stand up for the deepest values of our party...» [14] / «Вы знаете, во всех штатах вы голосовали за сильного лидера, который будет защищать ценности нашей партии...». Таким образом, говоря о результатах голосования, Х. Клинтон прямо не называла политика, победившего на выборах.

Тематика выступлений Х. Клинтон наилучшим образом прослеживается на материалах ее предвыборной программы. К ней относится промышленная, миграционная и социальная политика, вопросы вооружения, налоги, образование и торговля. Начиная свое выступление, Х. Клинтон часто использует вводные конструкции, к числу которых относились такие, как «l think», «Well» и проч. Это позволяет политику, приступая к освещению социально-значимых проблем в своем выступлении, сосредоточить внимание аудитории на своей речи, подготовить ее к восприятию актуальной информации, которую она хотела бы донести до граждан. Наряду с X. Клинтон, лексико-семантические и лексико-тематические особенности женщин-политиков на западе целесообразно рассмотреть на примере речевого портрета экс-госсекретаря США Кондолизы Райс. Она являлась второй женщиной после Мадлен Олбрайт, занявшей этот пост. Аналогично Х. Клинтон, в своих выступлениях она успешно сочетала как мужские, так и женские лексические особенности, при этом используя способ резкой смены гендерного стиля речи, о котором говорилось выше. Выступление К. Райс во время ее визита в Азию было тематически и семантически наполнено мужской лексикой. Конструкция выступления также была выстроена логично, последовательно. Обозначив цель своего визита, политик сразу перешла к детальному разъяснению содержания своей программы по пунктам: «The purpose of my trip is to rally the support of our friends and allies in Northeast Asia for our comprehensive strategy» [1, 
с. 247] / «Цель моей поездки - заручиться поддержкой наших друзей и союзников в Северо-Восточной Азии, чтобы совместными усилиями строить нашу дальнейшую стратегию». Четкое определение цели и задач своего визита свидетельствует о доминировании «мужских» стратегий в построении высказываний.

Для публичных выступлений К. Райз, аналогично Х. Клинтон, характерно обилие употребления вводных конструкций, которые позволяют политическому оратору, какой бы ни была коммуникация по своему содержанию, выиграть дополнительное время для обдумывания следующей фразы. В этой связи, можно сделать вывод, что это данный прием политической коммуникации является наиболее распространенным и часто используемым западными женщинами-политиками. В речи Кондолизы Райс встречаются такие вводные конструкции, как «From that day on», «l know too» и др. Необходимо также отметить, что они служат своего рода «мостиками», логическими связками между предшествующей темой в рамках выступления и той, к которой политик намерен перейти. Это позволяет также создать условия для более легкого восприятия аудиторией новых смысловых блоков информации.

Лексико-тематической особенностью речи К. Райс является частое обращение к «мужским» темам: войны, защиты других стран, угрозы национальной безопасности и проч. При этом для каждой из микротем выступления характерна логическая структура и последовательность. Помимо этого, семантика речи К. Райз рассчитана на воздействие на эмоциональную сферу слушателей, пробуждение в них чувства патриотизма, любви к своей родине, гордости за Соединенные Штаты. В патриотическую канву выступления политиком умело вплетаются темы и проблемы внутриполитической жизни, которые, на ее взгляд, требуют своевременного решения: «More than at any other time in history, greatness is built on mobilizing human potential and ambition. We have always done that better than any country in the world. People have come here from all over because they have believed our creed of opportunity and limitless horizons. ... We need immigration laws that protect our borders, meet our economic needs, and yet show that we are a compassionate nation of immigrants» [17] / «Более, чем когда-либо в истории, <американское> величие основано на мобилизации человеческого потенциала и амбиций. Мы всегда делали это лучше, чем любая другая страна в мире. Люди приезжали сюда отовсюду, потому что они поверили нашему кредо возможностей и безграничных горизонтов. ... Нам нужны иммиграционные законы, которые защищают наши границы, отвечают нашим экономическим потребностям и, в то же время, показывают, что мы нация, сострадающая иммигрантам».

При этом в тематике выступления К. Райз для RNC
(Национального комитета Республиканской партии), о чем свидетельствует стенограмма, преобладают сверхпатриотичные идеи, намеренно акцентируется внимание аудитории на американской исключительности по сравнению с любой другой страной мира: «After all, when the world looks to America, they look to us because we are the most successful economic and political experiment in human history. That is the true basis of American exceptionalism» [17] / «В конце концов, когда мир смотрит на Америку, они смотрят на нас, потому что мы - самый успешный экономический и политический эксперимент в истории человечества. Это истинная основа американской исключительности». Представляется, что подобные заявления в публичном выступлении нуждаются в фактическом подкреплении, о котором К. Райз, вероятно, имеет представление, но не обнародует его.

Несмотря на то, что семантическое наполнение выступления К. Райз имеет по преимуществу «маскулинный» характер, в нем прослеживается стремление политика к смене основного вектора повествования: к проблемам войны, патриотизма и проч. она переходит после рассмотрения не менее значимых экономических вопросов. Это дополнительно доказывает тесную взаимосвязь освещаемых проблем в ее выступлении. Если лексико-семантической особенностью политической составляющей выступлений К. Райз являются продуманные метафоры, призванные оказать глубокое воздействие на сознание личности, в рамках освещения экономических вопросов политик чаще придерживается стандартных выражений: «Then, in 2008, the global financial and economic crisis would stun us. And it still reverberates as we deal with unemployment and economic uncertainty and bad policies that cast a pall over an American economy and a recovery that is desperately needed at home and abroad» [17] / Затем, в 2008 году, мировой финансово-экономический кризис оглушит нас. Это все продолжает проявляться, когда мы имеем дело с безработицей, экономической неопределенностью и непродуманной политикой, что создает завесу над американской экономикой и восстановлением, отчаянно необходимым на родине и за границей». В свою очередь, анализ лексико-семантических и лексико-тематических особенностей в речи мужчин-политиков в рамках настоящей статьи будет производиться на примере текстов выступлений Б. Обамы - 44-ого президента Соединённых Штатов Америки, переизбранного на второй президентский срок в 2012 г., который завершился 20 января 2017 г. Выбор политика определяется связью, которая прослеживается в результате анализа и сопоставления его выступлений с текстами речей Х. Клинтон. Несмотря на осуждение последней внешнеполитического курса Б. Обамы, оба политика в лексике используют сходные приемы, определяющие особенности ее семантики, а именно - эвфемизмы. Во многом это было обусловлено стремлением Б. Обамы занять пост президента и скрыть определенные моменты В 
своих публичных выступлениях, которые могли быть неприятны народу Америки, сделав при этом акцент на его дальнейшем благополучном развитии.

Тексты речей Б. Обамы изобилуют примерами политических эвфемизмов в современной лингвистике. Б. Обама, прямо не обозначая вопрос расового и гендерного равенства граждан Соединенных Штатов, неоднократно пытается поднять его «завуалировано», при помощи намеков. В частности, в речи, которая была произнесена Б. Обамой в период выборов в 2012 г. семантика его выступления приобрела еще более яркую окраску в силу крайней степени сравнений, производимых бывшим президентом США: «Неважно, черный ты или белый, латиноамериканец, азиат или коренной американец, молодой или старый, богатый или бедный, дееспособный, инвалид, гей или натурал» [16]. При этом содержательный посыл речи Б. Обамы был призван вселить уверенность в сердцах американцев относительно будущего процветания не только их страны, но и лично каждого гражданина вне зависимости от обстоятельств.

Наряду с этим, эвфемизмы, к которым прибегает Б. Обама, обладают универсальностью, консолидирующим воздействием на аудиторию. Несмотря на полярность сравнений, которые использовал бывший президент, он апеллировал к многонациональности Америки, подчеркивал равенство в правах всех ее граждан без исключения.

Значимо использование Б. Обамой политических эвфемизмов в отношении физических возможностей граждан. Для людей, имеющих определенные отклонения в развитии, инвалидность и проч., велико значение акцента, сделанного бывшим президентом, на равенстве их возможностей вне зависимости от физических недостатков [16].

Это, в частности, определяет лексико-тематические особенности речевого портрета Б. Обамы. В то время как для его предшественника Дж. Буша основной темой публичных выступлений являлась борьба с внешней угрозой, Б. Обама склонен сосредотачиваться на внутренних проблемах страны, в частности, на борьбе с несовершенством курса в области экономики и политики, интригах в Конгрессе, уходе администрации от ответственности за свои действия, усовершенствовании работы систем образования и здравоохранения и проч. При этом поли- тика Кабинета Б. Обамы также выстраивается на основе принципов равенства. Политик призывает учиться на своих ошибках и всем гражданам быть ответственными за будущее Америки [10, с. 78].

Несмотря на то, что прямо Б. Обама не заявляет о кризисных явлениях в американской экономике, он призывает граждан страны к активным действиям. Тематика призыва, необходимости учитывать ошибки прошлого во имя лучшего будущего характерна для речей Б. Обамы, в частности, для его инаугурационного выступления: «An economic recovery has begun. America's possibilities are limitless, for we possess all the qualities that this world without boundaries demands: youth and drive; diversity and openness; an endless capacity for risk and a gift for reinvention. My fellow Americans, we are made for this moment, and we will seize it - so long as we seize it together» [15] / «Начался экономический подъем. Возможности Америки безграничны, поскольку мы обладаем всеми качествами, которые требует этот мир без границ: молодостью и энергией; разнообразие и открытость; бесконечная способность к риску и подарок для переосмысления. Мои сограждане-американцы, мы созданы для этого момента, и мы воспользуемся им - пока мы воспользуемся им вместе». П Подводя итоги, следует отметить, что рассмотрение лексико-семантических и лексико-тематических особенностей речевого портрета известных западных женщин-политиков и мужчин-политиков позволило прийти к выводу о наличии общих и отличных черт в реализуемых ими подходах к построению коммуникации.

В частности, женщинам-политикам в большей степени свойственна резкая смена семантики, переходы из одной предметной области выступления к другой, а также сочетание как «маскулинных», так и «фемининных» элементов в речи. Лексика мужчины-политика не имеет «фемининных» черт, равно как и резких переходов, смены смысла.

При этом тематика выступлений как женщин, так и мужчин-политиков является сходной, касающейся значимых для Соединенных Штатов вопросов внутренней и внешней политики. Она призвана воздействовать на эмоциональное состояние аудитории, обращена к чувству патриотизма граждан, гордости за свою страну, исходит из факта многонациональности американского народа.

\section{ЛИТЕРАТУРА}

1. Арустамян Р., Макурина М.А., Пирожкова И.С. Проявление гендерных особенностей в политическом дискурсе // Политическая лингвистика. 2016. 6 (60). - С. 244-249. [Электронный ресурс] - Режим доступа: URL: https://cyberleninka.ru/article/n/proyavlenie-gendernyh-osobennostey-v-politicheskom-diskurse (дата обращения: 18.04.2021).

2. Гордеева 0.И. Политический имидж в избирательной кампании // Технология и организация выборных кампаний. Зарубежный и отечественный опыт. M., 1993. - C. 158-171. 
3. Иран не имеет права на ядерное оружие - Хиллари Клинтон // PИА HОВОСТИ. 13.10.2009. [Электронный ресурс] - Режим доступа: URL: https://ria. ru/20091013/188720903.html (дата обращения: 18.04.2021).

4. К Клинтон заявила о необходимости наказать Иран в случае нарушения ядерного соглашения // Служба новостей «Голоса Америки». 15.09 .2015$. [Электронный ресурс] - Режим доступа: URL: https://www.golosameriki.com/a/clinton-vows-penalties-for-iran-for-any-nuclear-violations/2954968.html (дата обращения: 18.04.2021).

5. Почепцов Г.Г. Имидж: от фараонов до президентов: строительство воображаемых миров в мифе, сказке, анекдоте, рекламе, пропаганде и паблик рилейшнз. - Киев: АДЕФ-Украина, 1997. - 328 с.

6. Саурбаев Р.Ж., Шагбанова Х.С. Речевые стратегии политического новостного дискурса на материале британской прессы: монография. - М.: Новый индекс, 2020. - 104 c.

7. Стернин И.А. Модели описания коммуникативного поведения. - Воронеж: «Гарант», 2000. - 27с.

8. Фисенко В.В. Использование эвфемизмов как способ манипуляции в политическом дискурсе // Вестник ЛНУ им. Тараса Шевченко. 2010. № 20 (2007). Ч. 1. - С. 36-41.

9. Хиллари Клинтон: критику в адрес Обамы не надо считать личными нападками // TACC. 13.08.2014. [Электронный ресурc] - Режим доступа: URL: https:// tass.ru/mezhdunarodnaya-panorama/1376722 (дата обращения: 18.04.2021).

10. Шустова Е.В. Дискурс Барака Обамы: приемы и образы // Политическая лингвистика. 2010. № (2) 32. - С. 77-91.

11. Barack Obama's Inaugural Address // New York Times. Jan. 20, 2009. [Электронный ресурс] - Режим доступа: URL: https://www.nytimes.com/2009/01/20/us/ politics/20text-obama.html (дата обращения: 18.04.2021).

12. Borisoff D., Merrill L. The Power to Communicate: Gender Differences as Barriers. — Illinois: Prospect Heights, 1998. - $151 \mathrm{p}$.

13. Cooper C., Chozick A. Clinton, Obama Exchange Harsh Words In South Carolina Debate // The Wall Street Journal. Jan. 22, 2008. [Электронный ресурс] - Режим доступа: URL: https://www.wsj.com/articles/SB120096613305305235 (дата обращения: 18.04.2021).

14. Hillary Clinton's remarks at a rally on Tuesday in New York City. [Электронный ресурс] - Режим доступа: URL: https://www.telegraph.co.uk/news/worldnews/ democrats/2073000/Hillary Clintons-speech-Full-text.html (дата обращения: 18.04.2021).

15. President Barack Obama's inaugural address - full text. [Электронный ресурс] - Режим доступа: URL: https://www.theguardian.com/world/2013/jan/21/ barack-obama-2013-inaugural-address (дата обращения: 18.04.2021).

16. Read the Full Transcript of President Barack Obama's Farewell Speech // TIME. Jan. 10, 2017. [Электронный ресурс] - Режим доступа: URL: https://time. com/4631007/president-obama-farewell-speech-transcript/ (дата обращения: 19.04.2021).

17. Transcript of Condoleezza Rice speech at the RNC // Fox News. August 29, 2012. [Электронный ресурс] - Режим доступа: URL: https://www.foxnews.com/ politics/transcript-of-condoleezza-rice-speech-at-the-rnc (дата обращения: 18.04.2021). 